\title{
Waterlogging tolerance and recovery capability screening in peanut: a comparative analysis of waterlogging effects on physiological traits and yield
}

\author{
Ruier Zeng Equal first author, ${ }^{1}$, Jing Cao ${ }^{\text {Equal first author, }{ }^{1}, \mathbf{X i ~ L i}^{1} \text {, Xinyue Wang }}{ }^{1}$, Ying Wang ${ }^{1}$, Suzhe Yao ${ }^{1}$, Yu Gao ${ }^{1}$, Jing Hu ${ }^{1}$, \\ Mingzhu Luo ${ }^{1}$, Lei Zhang ${ }^{\text {Corresp., } 1}$, Tingting Chen ${ }^{\text {Corresp. } 1}$ \\ ${ }^{1}$ College of Agriculture, South China Agricultural University, Guangzhou, Guangdong, China \\ Corresponding Authors: Lei Zhang, Tingting Chen \\ Email address: zhanglei@scau.edu.cn, chentingting@scau.edu.cn
}

15 peanut varieties at the pod filling stage were exposed to waterlogging stress for 7 days, the enzyme activities and fluorescence parameters were measured after 7 days of waterlogging and drainage. The waterlogging tolerance and recovery capability of varieties were identified. After waterlogging, waterlogging tolerance coefficient (WTC) of relative electrolyte linkage (REL), malondialdehyde (MDA) content, superoxide dismutase (SOD) activity, and catalase (CAT) activity, non-photochemical quenching (NPQ) and photochemical quenching $(q L)$ of leaves of most peanut varieties were increased, while the WTC of the soil and plant analysis development (SPAD) value, PSIl actual quantum yield $\left(\Phi_{P S I I}\right)$, maximum photochemical efficiency $(\mathrm{Fv} / \mathrm{Fm})$ were decreased. After drainage, the WTC of REL, MDA content, SOD and CAT activity of leaves were decreased compared with that of after waterlogging, but these indicators of a few cultivars were increased. $\Phi_{\text {PSII, }}$ $\mathrm{Fv} / \mathrm{Fm}$ and $\mathrm{qL}$ can be used as important indexes to identify waterlogging recovery capability. There was a significant negative correlation between recovery capability and the proportion of reduction in yield, while no significant correlation was found between waterlogging tolerance and the proportion of reduction in yield. Therefore, it is recommended to select varieties with high recovery capability and less pod number reduction under waterlogging in peanut breeding and cultivation. 


\section{Waterlogging tolerance and recovery capability screening in}

2 peanut: a comparative analysis of waterlogging effects on

3 physiological traits and yield

4

5 Ruier Zeng†, Jing Cao†, Xi Li, Xinyue Wang, Ying Wang, Suzhe Yao, Yu Gao, Jing Hu,

6 Mingzhu Luo, Lei Zhang*, Tingting Chen*

7

8 9

College of Agriculture, South China Agricultural University, Guangzhou, 510642, China

Corresponding Author:

Lei Zhang, zhanglei@scau.edu.cn; Tingting Chen, chentingting@scau.edu.cn

Department of Crop Science and Technology, College of Agriculture, South China Agricultural University, Guangzhou, 510642, PR China

\begin{abstract}
15 peanut varieties at the pod filling stage were exposed to waterlogging stress for 7 days, the enzyme activities and fluorescence parameters were measured after 7 days of waterlogging and drainage. The waterlogging tolerance and recovery capability of varieties were identified. After waterlogging, waterlogging tolerance coefficient (WTC) of relative electrolyte linkage (REL), malondialdehyde (MDA) content, superoxide dismutase (SOD) activity, and catalase (CAT) activity, non-photochemical quenching (NPQ) and photochemical quenching (qL) of leaves of most peanut varieties were increased, while the WTC of the soil and plant analysis development (SPAD) value, PS II actual quantum yield $\left(\Phi_{P S} I\right)$, maximum photochemical efficiency $(\mathrm{Fv} / \mathrm{Fm})$ were decreased. After drainage, the WTC of REL, MDA content, SOD and CAT activity of leaves were decreased compared with that of after waterlogging, but these indicators of a few cultivars were increased. $\Phi_{P S I}, \mathrm{Fv} / \mathrm{Fm}$ and $\mathrm{qL}$ can be used as important indexes to identify waterlogging recovery capability. There was a significant negative correlation between recovery capability and the proportion of reduction in yield, while no significant correlation was found between waterlogging tolerance and the proportion of reduction in yield. Therefore, it is
\end{abstract}


30

31

32

33

34

35

36

37

38

39

40

41

42

43

44

45

46

47

48

49

50

51

52

53

54

55

56

57

58

59

60

recommended to select varieties with high recovery capability and less pod number reduction under waterlogging in peanut breeding and cultivation.

Keywords Arachis hypogaea L., Abiotic stress, Varities, Comprehensive evaluation, Waterlogging tolerance, Recovery capability

\section{Introduction}

Waterlogging is one of the limiting factors affecting plant growth and development, resulting in a sharp yield decline and huge economic losses (Bailey-Serres et al., 2012). Waterlogging causes hypoxia in plant roots, and acetaldehyde, ethanol and other substances produced by anaerobic metabolism in roots are toxic to root cells, which inhibits carbon assimilation and photosynthate utilization (Aydogan \& Turhan, 2015; Gao et al., 2021). Besides, waterlogging breaks the dynamic balance of plant reactive oxygen species production and scavenging (Hu et al., 2020), resulting in the accumulation of reactive oxygen radicals in plants and membrane lipid peroxidation and cell dysfunction (Liu et al., 2010; Wei et al., 2013). Waterlogging also resulted in a decrease in photosynthetic rate, leaf yellowing and wilting. Therefore, plant growth is inhibited and eventually leads to the decrease of total biomass and yield (Tian et al., 2021; Zhang et al., 2019).

Peanut (Arachis hypogaea L.) is a widely planted leguminous crop in the world. As an important source of oil and protein for human beings, peanut has high nutritional value and a wide range of uses (Bishi et al., 2015; Zhao et al., 2019). In China, due to excessive rainfall, the peanut field was flooded, which severely restricted the peanut production (Zeng et al., 2020). Previous studies have revealed that the photosynthetic system of the waterlogged peanut leaves was destroyed, limiting the $\mathrm{CO}_{2}$ assimilation rate and reducing the photosynthetic efficiency of peanut leaves. The most susceptible growth stage of peanut to waterlogging was the pod filling stage, and waterlogging at the pod filling stage significantly reduced the pods number per plant and pod weight, and ultimately led to peanut yield decline (Zeng et al., 2020; Bishnoi \& Krishnamoorthy, 1992). With global warming, the growth and development of peanut plants are facing an increasing risk of waterlogging (Schiermeier, 2011). Therefore, identifying and screening peanut varieties with high waterlogging tolerance has become a critical problem to be addressed urgently in the peanut production areas of China. 
61 As we know, the waterlogging tolerance of peanut is a complex and comprehensive trait, so it 62 is significant to develop an effective method to screen waterlogging tolerant peanut varieties.

63 The recuperative potential from stress is of great significance for plant vitality and survival

64 (Galle et al., 2007; Shi et al., 2016). And combining the physiological and growth characteristics 65 of various varieties after waterlogging and during the recovery stage is an effective method to 66 identify the waterlogging tolerance of different varieties (Ciancio et al., 2021; Aydogan \& 67 Turhan, 2015; Pompeiano et al., 2019). A study on mungbean suggested that selecting the 68 genotype with the least decrease in chlorophyll fluorescence after drainage was beneficial for 69 screening a large number of waterlogging tolerant varieties (Aydogan \& Turhan, 2015). Besides, the ability to conserve water content and high photosynthetic capacity through stomatal control was important for the regrowth of kiwifruit vines (Li et al., 2020). Meanwhile, in agricultural production, only the maximum yield can ensure the output of farmland and the income of farmers. However, waterlogging affects the yield and yield components. For example, waterlogging reduced the number of spikelets per plant, the number of kernels per spikelet or the grain weight, resulting in the wheat yield decline (Arduini et al., 2019; Hossain et al., 2011). Therefore, we suggest that comprehensive consideration of the changes of each index after waterlogging and drainage, combined with the final yield and yield components, can better evaluate the response of different peanut varieties to waterlogging, which provides a foundation 79 for waterlogging tolerance breeding and high-yield cultivation.

At present, the comprehensive evaluation of multiple indicators of peanut to waterlogging needs to be further studied. In this experiment, the soil and plant analysis development (SPAD) value, chlorophyll fluorescence parameters, and enzyme activities of 15 peanut varieties after 7 days of waterlogging and 7 days of drainage were measured, combined with the yield and yield components of peanut at the harvest stage. Waterlogging tolerance and recovery capability of different peanut varieties were classified by principal component analysis, membership function analysis, and cluster analysis. The main screening indexes to identify the waterlogging tolerance and recovery capability of plants were determined. And the relationships between waterlogging tolerance, recovery capability, yield and yield components of different peanut varieties were discussed, exploring the response mechanism of different peanut varieties to waterlogging stress and establishing a reliable comprehensive evaluation method for identifying peanut waterlogging 
91 tolerance. And this study lays a foundation for selecting waterlogging tolerant varieties and the 92 evaluation of waterlogging tolerance varieties in the peanut production areas of China.

Materials \& Methods

95 Plant materials

96 Fifteen peanut varieties were selected as plant materials in this experiment, and the details of the

97 materials were given in Table 1. The field experiment was conducted at the Zengcheng Teaching 98 and Research Farm (23⒉ $4^{\prime}$ N, $113^{\circ} 64^{\prime}$ E) of South China Agricultural University (SCAU), 99 which is located in Zengcheng District, Guangzhou City, Guangdong Province, China.

100 Waterlogging treatment

101 Seeds of per variety were planted in three replicate plots. Waterlogging treatment was applied to 102 peanut plants during the pod filling stage, and the water level was kept at $2 \mathrm{~cm}$ higher than the 103 soil surface during the waterlogging process. And the blank control group of each variety was 104 also set, During the growth stage, the CK groups of all varieties were irrigated normally and kept 105 the soil moisture at $75-80 \%$ of saturated water-holding capacity. The water in the fields was 106 drained after waterlogging for 7 days. Other management practices followed conventional 107 cultivation methods.

\section{Determination of SPAD value and chlorophyll fluorescence parameters}

109

110

111

112

113

114

115

116

117

118

119

120

121

After 7 days of waterlogging and 7 days of drainage, the SPAD value in the functional leaves of the main stem (from the top of the main stem to the base of the stem, the third open leaf) was measured using a chlorophyll meter (SPAD-502; Konica Minolta Sensing, Inc., Osaka, Japan). Chlorophyll fluorescence parameters of the same leaf were analyzed using a hand-held device MultispeQ Beta (Kuhlgert et al., 2016). And PS II actual quantum yield ( $\left.\Phi_{P S} I\right)$, maximum photochemical efficiency (Fv/Fm), non-photochemical quenching (NPQ), and photochemical quenching $(\mathrm{qL})$ of leaves were obtained. Three functional leaves were measured in each plot. The data of one plot was a replicate, and each treatment contained three replicates.

\section{Determination of the activities of SOD and CAT}

SOD activity was measured by monitoring the inhibition of nitro blue tetrazolium (NBT) reduction with a spectrophotometer at $560 \mathrm{~nm} ; 100 \mu \mathrm{L}$ of crude enzyme solution was added to $2.9 \mathrm{~mL}$ reaction solution, which was composed of $50 \mathrm{mM}$ sodium phosphate buffer ( $\mathrm{pH} 7.8$ ), 60 $\mu \mathrm{M}$ riboflavin, $195 \mathrm{mM}$ methionine, $3 \mu \mathrm{M}$ ethylenediamine tetraacetic acid (EDTA), and 1.125 
$122 \mathrm{mM} \mathrm{NBT} ; 3 \mathrm{~mL}$ reaction solution was used as the control. The mixture was placed under a 4000

123 lx fluorescent lamp for $60 \mathrm{~min}$ for chromogenic reaction, and then turned into the darkness to 124 stop the reaction. One unit of SOD activity was defined as the amount of enzyme that inhibits the 125 NBT reduction by $50 \%$.

126 For estimating the CAT activity, $100 \mu \mathrm{L}$ of enzyme extract was added to a mixture 127 containing $5.9 \mathrm{mM}$ of $\mathrm{H}_{2} \mathrm{O}_{2}$ and $50 \mathrm{mM}$ of buffer. Recording the absorbance at $240 \mathrm{~nm}$ at per 128 minute interval for $3 \mathrm{~min}$. A unit of CAT activity was defined as the changes in absorbance at $129240 \mathrm{~nm}$ per minute.

\section{Determination of MDA content}

131 MDA content was calculated by the thiobarbituric acid (TBA) method described by a previous 132 report with modifications (Wassie et al., 2019). Fresh leaf samples $(0.5 \mathrm{~g})$ were put into liquid 133 nitrogen and ground to powder, then were homogenized in $2 \mathrm{~mL}$ of $10 \%(\mathrm{v} / \mathrm{v}) \mathrm{TCA}$ solution, 134 followed by centrifugation at $3,000 \times \mathrm{g}$ for $10 \mathrm{~min}$ and collection of the supernatant. The $2 \mathrm{~mL}$ 135 obtained supernatant was added to an equal volume of reaction mixture, which contained $20 \%$ $136(\mathrm{v} / \mathrm{v})$ trichloroacetic acid and $0.5 \%(\mathrm{v} / \mathrm{v})$ thiobarbituric acid. The mixture was then heated at 100 $137{ }^{\circ} \mathrm{C}$ water bath for $20 \mathrm{~min}$ and then was stopped by an ice bath, followed by centrifugation at 4 , $138000 \mathrm{~g}$ for $10 \mathrm{~min}$ at $20^{\circ} \mathrm{C}$. To determine the MDA level, the supernatant absorbance was 139 measured spectrophotometrically at 450,532 , and $600 \mathrm{~nm}$.

\section{Determination of relative electrolyte linkage (EL)}

141 Electrolyte leakage was measured following the method described by the method of predecessors

142 (Huang et al., 2017). $1.0 \mathrm{~g}$ fresh leaf samples were washed with deionized water for 3 times and 143 then transferred to a 50-mL centrifuge tube containing deionized water. The test tube was 144 cultured in a conical shaker at room temperature for 12 hours, and a conductivity meter (Jenco145 3173, Jenco Instruments, Inc., San Diego, CA, USA) was used to measure the initial electrical 146 conductivity (EL1). Then the leaves were sterilized at $100^{\circ} \mathrm{C}$ for $30 \mathrm{~min}$, then cooled at room 147 temperature, and the secondary conductivity (EL2) of the leaves was measured. The relative 148 electrolyte linkage (REL) is calculated by the formula:

$$
\operatorname{REL}(\%)=(E L 1 / E L 2) \times 100 \text {. (1) }
$$

\section{Determination of yield and yield components}

151 Plant samples were harvested on 15 December 2020 for the determination of the yield and yield 152 components. The representative plant samples from each plot were obtained at the physiological 
153 maturity stage to determine the yield and yield components, including the pod yields per hectare 154 (Y), the number of total pods per plant (TP), the hundred pods weight (HPW), and the hundred 155 kernels weight (HKW). The proportion of reduction in yield and yield components is also 156 calculated, including the proportion of reduction in yield (RY), the proportion of reduction in 157 HPW (RHPW), the proportion of reduction in HKW (RHKW), and the proportion of reduction in 158 TP (RTP). The data of one plot was a replicate, and each treatment contained three replicates.

\section{Evaluation of waterlogging tolerance}

160 The waterlogging tolerance coefficient $(W T C)$ of all indicators was calculated using the 161 following equation:

$$
W T C=(W K / C K) \times 100 .(2)
$$

where $\mathrm{CK}$ is the mean value of an indicator under the control treatment and $\mathrm{WK}$ is the mean value of an indicator under waterlogging treatment.

Membership function values of various indicators of different varieties:

$$
u\left(X_{j}\right)=\left(X_{j}-X_{\min }\right) /\left(X_{\max }-X_{\min }\right)(j=1,2, \rrbracket, n) .
$$

where $\mu\left(X_{j}\right)$ represents the subordinate function value of the $j$-th comprehensive indicator, $X j$ represents the $j$-th comprehensive indicator value, $X_{\max }$ represents the maximum value of the $j$-th comprehensive indicator, and $X_{\min }$ represents the minimum value of the $j$-th comprehensive indicator.

The index weight calculation formula of each comprehensive indicator is as follows:

$$
w_{j}=p_{j} / \sum_{j=1}^{n} p_{j}(j=1,2, \rrbracket, n)
$$

where $w_{j}$ is the index weight of the $j$-th comprehensive indicator among all comprehensive indicators and $p_{j}$ is the contribution rate of the $j$-th comprehensive indicator.

The comprehensive evaluation value of waterlogging tolerance of different peanut varieties:

$$
D=\sum_{j}^{n}\left[u\left(X_{j}\right) \times w_{j}\right](j=1,2, \square \quad n)
$$

where $\mathrm{D}$ indicates the comprehensive evaluation value of waterlogging tolerance of peanut varieties. The higher the $\mathrm{D}$ value, the stronger the tolerance to waterlogging stress of peanut 
182 varieties; the lower the D value, the weaker the tolerance to waterlogging stress of peanut 183 varieties.

184 Statistically analysis

185 Experimental data was statistically analyzed using Microsoft Excel 2010 and SPSS 22.0 (SPSS., 186 Chicago, IL, USA), and the image was generated using Origin 2017. All data are means of three 187 replicates $(\mathrm{n}=3)$. Comparisons among multiple groups were performed using Fisher's protected 188 least significant difference (LSD) test. Probability values $p<0.05$ were considered statistically 189 significant. SPSS 22.0 software was used for variance analysis, principal component analysis, 190 and cluster analysis of data. And the D value of different varieties was analyzed by cluster 191 analysis at an Euclidean distance of 5.

192

\section{Results}

194 Response of different indexes to waterlogging and correlation analysis among them 195 Supplementary Figure 1-10 displayed the response of leaf indexes of 15 peanut varieties to 7 196 days of waterlogging and 7 days of drainage. Waterlogging significantly affected the 197 photosynthetic characteristics and antioxidant capacity of peanut leaves. However, there were 198 great differences in the response of different varieties to waterlogging. As shown in Table 2, 199 after waterlogging for 7 days, the WTC of REL, MDA content, SOD activity, and CAT activity, 200 NPQ and qL of leaves of some peanut varieties (HH 2, YH 65, YH 22) increased, and the WTC 201 of SPAD value, $\Phi_{P S ~ I I}, \mathrm{Fv} / \mathrm{Fm}$ of peanut varieties (KN 1715, DBW and SLLK) decreased. After 7 202 days of drainage, the WTC of REL, MDA content, SOD activity and CAT activity of leaves of 203 peanut variety YY 45 decreased compared with that of 7 days of waterlogging, but these 204 indicators of YSHS still increased. And after drainage, the WTC of SOD activity and CAT 205 activity of leaves of peanut varieties (KN 1715, JH 7) decreased compared with that of after 206 waterlogging for 7 days, but these indicators of (YY 13, HH 2, DBW, HY 10, and HJ 16) still 207 increased. Besides, after 7 days of drainage, $\Phi_{P S ~ I}$, Fv/Fm, NPQ and qL increased or decreased 208 to different degrees in comparison with those after 7 days of waterlogging. And the WTC of 209 HPW, HCW, Y, and TP of most varieties (YYHS, HH 2, KN 1715, HY 4, DBW, YH 65, YH 22 , $210 \mathrm{JH}$ 7, HY 10, FH 1, JH 16, and HY 39) decreased, indicating that waterlogging had a negative 211 impact on yield and yield components. 
212 Besides, from the correlation coefficient matrix (Table 3), there was a positive correlation 213 between $\mathrm{Fv} / \mathrm{Fm}$ and SPAD value of different peanut varieties after 7 days of waterlogging and 7 214 days of drainage (0.646 and 0.518, respectively). Meanwhile, HPW and HKW showed an 215 extremely significant positive correlation (0.829), and Y was significantly positively correlated 216 with TP (0.820). However, there may be information overlap between different indicators, and 217 every single indicator plays a different role in the waterlogging tolerance of peanut. Therefore, it 218 is difficult to accurately evaluate the waterlogging tolerance of different peanut varieties by 219 using these indicators directly. To make up the deficiency of a single indicator evaluation of 220 waterlogging tolerance, the principal component analysis method was used.

221

Comprehensive evaluation of waterlogging tolerance of different peanut varieties 223 Principal component analysis, membership function analysis and comprehensive evaluation To eliminate the factors with small influence and large interference and improve the accuracy of measurement data analysis, the above single indicator was converted into a fewer and more effective indicator. Therefore, Principal component analysis was conducted based on the WTC of 9 indicators of 15 peanut cultivars after waterlogging for 7 days. As shown in Table 4, three principal components were selected. And the contribution rates of the comprehensive indexes $C_{1}$ to $C_{3}$ were $36.759 \%, 24.092 \%$, and $11.244 \%$, respectively, and the eigenvalue was 3.308 , 2.168 , and 1.299 , respectively. The cumulative contributions to the total variation of the population from first to third of principal component reached over $75.289 \%$, which represented that the tested materials could be used for further analysis.

According to Equation (3), the membership function values of all the comprehensive indexes of different peanut varieties were obtained (Table 5). From the perspective of a single comprehensive index, such as $C I_{1}$, the $u\left(X_{1}\right)$ of HY 39 is the largest, which is 1.0000 , indicating that HY 39 has the strongest tolerance to waterlogging in $C I_{1}$. On the contrary, the $u\left(X_{1}\right)$ of SLLK is the smallest, which is 0.0000 , indicating that SLLK has the weakest tolerance to waterlogging in this comprehensive index. Since the contribution rates of comprehensive indexes $C I_{1} \sim C I_{3}$ are different, Equation (4) is used to calculate the weights of each comprehensive index,

240 which are $0.4882,0.3200$, and 0.1918 , respectively. 
242 The higher the D1 value, the stronger the tolerance to waterlogging stress of peanut varieties; 243 the lower the D1 value, the weaker the tolerance to waterlogging stress of peanut varieties. As

244 indicated in Table 5, the D1 value of YY 45 ranked first, followed by HY 4, and the D1 value of 245 SLLK ranked last, indicating that YY 45 has the highest waterlogging tolerance while SLLK has 246 the lowest. Therefore, we used the hierarchical cluster analysis to cluster D1 values. Figure 1 247 displayed that 15 peanut varieties could be divided into three categories: waterlogging-tolerant 248 varieties (HY 4, YY 45, YY 13, YH 65, and HY 39), intermediate varieties (FH 1, JH 16, KN 249 1715, YH 22, JH 7, HH 2, HY 10, and YSHS) and waterlogging-sensitive varieties (DBW and 250 SLLK).

251

252

Comprehensive evaluation of recovery capability of different peanut varieties 253 Principal component analysis, membership function analysis and comprehensive evaluation

254

255

256

257

258

259

260

261

262

263

264

265

266

267

268

269

270

271

272

A principal component analysis was also conducted based on the WTC of 9 indicators of 15 peanut cultivars after drainage for 7 days, and four principal components were selected (Table 6). And the contribution rates of the comprehensive indexes $C I_{1}$ to $C I_{4}$ were $30.493 \%, 19.614 \%$, $15.385 \%$, and $13.022 \%$, respectively, and the eigenvalue was $2.744,1.765,1.385$, and 1.172 , respectively. The cumulative contributions to the total variation of the population from first to fourth of principal component reached over $78.514 \%$, which indicated that the tested materials could be used for further analysis. And the membership function values of all the comprehensive indexes of different peanut varieties were obtained according to Equation (3) (Table 7). Equation

(4) is used to calculate the weights of each comprehensive index, which are $0.3884,0.2498$, 0.1960 , and 0.1659 , respectively.

\section{Cluster analysis of different peanut varieties based on D2 value after 7 days of drainage}

The higher the D2 value, the higher the recovery capability of peanut varieties; the lower the D2 value, the lower the recovery capability of peanut varieties. Therefore, we used the hierarchical cluster analysis to cluster D2 values. The D2 value of YY 13 ranked first, followed by YSHS, and the D2 value of SLLK ranked last, indicating that YY 13 has the highest recovery capability while SLLK has the lowest (Table 7). Figure 1 revealed that 15 peanut varieties could be divided into three categories: varieties with high recovery capability (YSHS, YY 13, HH 2, HY 4, and FH 1), varieties with intermediate recovery capability (YH 65, YH 22, JH 7, JH 16, HY 39, YY 45, and DBW), varieties with low recovery capability (KN 1715, HY 10, and SLLK). 
273

274 The indicators used for identifying waterlogging tolerance and recovery capability and 275 their relationship with yield and yield components

276 Correlation analysis was carried out between the D1 value and the WTC of each physiological 277 index after 7 days of waterlogging (Table 8). The D1 value strongly and positively correlated 278 with the $\Phi_{P S I}(\mathrm{~W}), \operatorname{SPAD}(\mathrm{W}), \mathrm{Fv} / \mathrm{Fm}(\mathrm{W})$, and the correlation coefficient was $0.845,0.845$, 2790.708 , respectively. Besides, there was a significant negative correlation between NPQ(W) and 280 D1 value, and the WTC was -0.707. Therefore, the WTC of $\Phi_{P S}(\mathrm{~W}), \mathrm{NPQ}(\mathrm{R}), \mathrm{Fv} / \mathrm{Fm}(\mathrm{W})$, and 281 SPAD values measured after 7 days of waterlogging can be used as important indexes for the 282 identification of waterlogging tolerance.

283 The correlation between D2 value and the WTC of each physiological index after 7 days of 284 drainage was also analyzed (Table 9). A significant positive correlation of D2 value was 285 observed with $\Phi_{P S ~ I I}(\mathrm{D})(\mathrm{r}=0.855)$. And there was a positive relation between $\mathrm{D} 2$ value and $286 \mathrm{Fv} / \mathrm{Fm}(\mathrm{D})(\mathrm{r}=0.625)$. However, there was a significant negative correlation between NPQ(D) 287 and D2 value, and the correlation coefficient was -0.609. Therefore, the WTC of $\Phi_{P S ~ I I}(\mathrm{D})$, $288 \mathrm{Fv} / \mathrm{Fm}(\mathrm{D})$ and NPQ(D) measured after 7 days of drainage can be used as important indexes for 289 the identification of recovery capability.

290 To determine the relationship between D1 value, D2 value, and the proportion of reduction 291 in yield and yield components, a linear model among them was fitted. As shown in Figure 2, the $292 \mathrm{R}^{2}$ between the RTP and RY is the highest (0.6732), followed by the $\mathrm{R}^{2}$ between the D2 value 293 and the RY (0.4458). In conclusion, both the D2 value and the RTP have significant effects on 294 the final yield. The lower the RTP and the higher the D2 value, the less the yield loss under 295 waterlogging. However, there was no significant correlation between the D1 value and RY. In 296 addition, no significant correlation was found between the D1 value and D2 value, suggesting 297 that the waterlogging tolerance of the variety did not affect the recovery capability.

Yield and yield components of peanut varieties with different waterlogging recovery 300 capability

301 Peanut with different recovery capacities had different yield decline under waterlogging stress 302 (Figure 3). For example, YY 13 is a cultivar with high recovery capability and YY 45 is a 
303 cultivar with intermediate recovery capability. And RTP of the two cultivars were $-1.67 \%$ and $3043.51 \%$. However, the RY of YY 13 was only $2.71 \%$, while that of YY 45 was 39.76\%. Besides, 305 HH 2 belongs to the variety with high recovery capability, and YH 65 belongs to the variety with 306 intermediate recovery capability. It is found that the TP of the two varieties decreased by $34.89 \%$ 307 and $33.40 \%$ respectively under waterlogging, which did not reach a significant difference, but 308 the yield of HH 2 decreased by $49.86 \%$, while the yield of YH 65 decreased by $56.61 \%$. It 309 showed that the recovery capability of peanut affected the final pod yield.

310 And among peanut varieties with similar recovery capability, the RY varied greatly among 311 varieties. Among the cultivars with high recovery capability (YY 13, YSHS, HH 2, FH 1, HY 4), 312 the D2 values of YY 13 and HY 4 were 0.6909 and 0.6447 , respectively, but the RY of YY 13 313 and HY 4 was $2.71 \%$ and $56.32 \%$, respectively. The RTP of YY 13 was $1.67 \%$ while that of HY 3144 was $44.21 \%$. In cultivars with intermediate recovery capability (YY 45, JH 7, JH 16, YH 65, 315 YH 22, DBW, HY 39), the yield of YY 45 and HY 39 decreased by $38.62 \%$ and $70.08 \%$, 316 respectively, and the TP of YY 45 increased by $3.47 \%$ while that of HY 39 decreased by 317 $60.91 \%$. In the cultivars with low recovery capability, including HY 10, SLLK, and KN 1715, 318 the RTP of HY 10, SLLK, and KN 1715 was $39.03 \%, 59.85 \%$ and $64.07 \%$, respectively, and the 319 RY of them was $62.35 \%, 60.46 \%$ and $78.74 \%$, respectively. The results indicated that the yield 320 of the peanut varieties with lower recovery capability decreased greatly, while the yield of the 321 peanut varieties with the same recovery capability was affected by RTP.

322

323 Discussion

324 Peanut is abundant in oil and protein, which is not only an important oil crop, but also an 325 important raw material for the food industry, medicine, and other industries, playing a critical 326 role in economic development and agricultural development (Latif et al., 2013). Previous studies showed that waterlogging led to peanut rotten pods and finally lead to yield penalty (Bishnoi \& Krishnamoorthy, 1992; Zeng et al., 2020). Due to the rising greenhouse gas levels, the likelihood 329 of extreme rainfall may have doubled (Smethurst \& Shabala, 2003). Therefore, the establishment of a comprehensive evaluation system to evaluate the waterlogging tolerance of peanut is of great significance to cultivation and breeding.

332 Different peanut varieties have different response mechanisms to waterlogging stress.

333 Waterlogging stress would finally lead to cellular and membrane damage and loss of 
334 photosynthetic capacity of plant leaves (Zhang et al., 2015; Smethurst \& Shabala, 2003; Irving et 335 al., 2007; Singh et al., 2019). However, plants exposed to waterlogging are prone to damage at 336 the cellular level and cause irreversible metabolic dysfunctions leading to cell death (Pereira et 337 al., 2015). After drainage, in some plants, such as soybean, levels of photosynthetic pigments 338 increased to pre-waterlogging level, and the enzyme activities of SOD and CAT returned to the 339 normal level compared with the treatment without waterlogging (Seymen, 2021), but other study

340 found that waterlogging stress release by soil drainage did not improve plant performance but, on 341 the contrary, enhanced oxidative stress and even accelerated plant injury (Hossain et al., 2009).

342 In this study, waterlogging led to the increase in REL, SOD activities, CAT activities, and MDA 343 content, and the decrease of SPAD value and $\mathrm{Fv} / \mathrm{Fm}$ in leaves of most peanut varieties, which 344 demonstrated that the photosynthesis of most peanut cultivars was restricted after waterlogging 345 stress, and reactive oxygen species and free radicals were accumulated in the cells of peanut. 346 Besides, the indexes (physiological and biochemical parameters) of some varieties could return 347 to the normal level after 7 days of drainage, indicating that for some peanut varieties, their 348 physiological and biochemical parameters can be restored to normal levels after drainage. 349 Clearly, waterlogging caused irreversible damage to the photosynthetic system and antioxidant 350 system of these peanut varieties. But the tolerance of different peanut varieties to waterlogging could not be comprehensively evaluated based on the changes of these indexes.

352 Membership function analysis, principal component analysis, and cluster analysis have been 353 widely used in plant tolerance evaluation (Liu et al., 2020; Aghaie et al., 2018; Seymen, 2021).

354 The membership function analysis is often used for the comprehensive evaluation of crop 355 waterlogging stress. However, there are some limitations on the comprehensive evaluation of 356 waterlogging tolerance by the membership function analysis for the correlation between indicators (Pancardo et al., 2021). Besides, the principal component analysis can convert the 358 original indexes into new comprehensive and independent indicators (Köksal, 2011). Therefore, 359 on this basis, by weighing the value of each comprehensive index and the corresponding membership function value of varieties, the comprehensive evaluation value of each genotype can be obtained, so as to comprehensively evaluate the tolerance of different varieties ( $\mathrm{Li}$ et al., 362 2018; Zhou et al., 2019). Therefore, to better clarify the response mechanism of peanut varieties 363 to waterlogging, we evaluated the physiological indexes measured at 7 days of waterlogging and 3647 days of drainage, respectively, and discussed the waterlogging tolerance and recovery 
365 capability of different peanut varieties. Results suggested that there were great differences in 366 waterlogging tolerance and recovery capability among various peanut varieties. However, linear

367 fit model revealed that there was no significant relationship between waterlogging tolerance and

368 recovery capability, which indicated that varieties with high waterlogging tolerance did not

369 necessarily have high recovery capability. For example, peanut varieties YY 45, YH 65, and

370 Huayu 39, have high waterlogging tolerance, but their recovery capacity is not the strongest. In

371 addition, we also found that the recovery capacity of varieties with weak waterlogging tolerance 372 was also weak.

373 Prior studies indicated that recovery of physiological and biochemical parameters after

374 drainage was closely related to the survival of plants under adverse conditions (Tian et al., 2021;

375 Pompeiano et al., 2019). Linear fit model showed that there was no correlation between D1 value 376 and the RY, and there was a significant negative correlation between the D2 value and the RY,

377 indicating that the recovery capability after waterlogging was crucial to the final pod yield.

378 While the study on cowpea suggested that the cultivars with higher drought tolerance were able 379 to maintain higher photochemical activity and leaf gas exchange during water deficit than the 380 sensitive cultivar did, which could alleviate the stress effects to the photosynthetic machinery 381 and improve its recovery ability (Rivas et al., 2016). And after waterlogging, the ability of 382 legumes to retain green leaves was essential to succeed during recovery (Striker et al., 2019).

383 Our study found that there was no significant difference in the RTP between YY 13 and YY 45, 384 but there was a significant difference in the RY, which was speculated to be due to the different 385 recovery capabilities of the two varieties. YY 13 had high recovery capability while YY 45 had 386 intermediate recovery capability. And the same pattern was also observed between cultivars $\mathrm{HH}$ 3872 and YH 65 . However, the recovery capacity of peanut variety was not the only factor that 388 determined the final yield. The results showed that the RY was also related to the RTP, 389 indicating that TP was affected under waterlogging. Besides, among the varieties with the same 390 recovery capability, only the varieties with the lower RTP have less yield loss. For example, 391 YY13 and YY45 were varieties with high recovery capability, but the decrease in TP of YY45 392 was higher than that of YY13. Therefore, the RTP was crucial to the final yield, which was in 393 agreement with the linear fit analysis (Figure 2). Therefore, the varieties with low recovery 394 capability should not be considered when breeding, and the varieties with high recovery 395 capability can be selected. In this study, we found that chlorophyll fluorescence parameters 
396 (ФPS II, SPAD, Fv/Fm) were also important indicators to identify the recovery capability. This

397 is similar to the results of previous researches (Wu et al., 2015; Smethurst et al., 2005).

398 Therefore, it is suggested to select cultivars with smaller RTP under waterlogging. Also, the 399 results of this study have a certain guiding significance for waterlogging tolerance breeding. We 400 also think that varieties with higher waterlogging recovery ability should be selected in 401 cultivation. It is indispensable to build water conservation projects and to drain water in time 402 after waterlogging (Garrity \& Pernito, 1996; Tian et al., 2019). At the same time, after 403 waterlogging, taking appropriate measures to improve the recovery capability of peanut plants is 404 necessary.

405 This study also showed that the variation trend of the same index of different peanut varieties 406 was very different under the waterlogging stress and during the recovery process. At present, 407 there are few studies on the physiological and biochemical response mechanism of peanut under 408 waterlogging stress, and no comprehensive method has been provided for the comprehensive 409 evaluation of its waterlogging tolerance. Many studies have shown that there is a correlation 410 between waterlogging tolerance and morphological, physiological, and other indexes, so this 411 study makes a comprehensive evaluation of several single indexes. The $\mathrm{D}$ value of each variety 412 was obtained according to the weight of the corresponding comprehensive index, and the 413 waterlogging tolerance and recovery capacity of each variety were obtained based on the $\mathrm{D}$ value. 414 Meanwhile, for the first time, the relationship between waterlogging tolerance and recovery 415 capacity and yield and yield components was discussed. This method can make up for the one416 sidedness of single index analysis, the results obtained are more objective and scientific, and 417 provide a reliable basis for practical application.

418

\section{Conclusions}

420 Different peanut varieties have different responses to waterlogging and drainage. It was found 421 that some physiological and biochemical parameters of some peanut varieties could return to 422 normal levels after drainage, but some varieties suffered irreversible damage from waterlogging. 423 There was no significant relationship between waterlogging tolerance and recovery capability of 424 different varieties, but there was a significant negative correlation between recovery capability 425 and yield decline. Correlation analysis showed that fluorescence parameters $\left(\Phi_{P S ~ I}, \mathrm{Fv} / \mathrm{Fm}, \mathrm{qL}\right)$ 426 can be used as important screening indexes to identify the waterlogging recovery capability. It is 
427 a feasible method for breeding and cultivation to select cultivars with higher recovery capability

428 and less reduction in pod numbers under waterlogging.

429

430 Acknowledgements

431 The authors are grateful to the reviewers and editors for their review and suggestions for this 432 paper.

433

434 References

435 Aghaie, P., Hosseini Tafreshi, S.A., Ebrahimi, M.A., and Haerinasab, M. 2018. Tolerance 436 evaluation and clustering of fourteen tomato cultivars grown under mild and severe drought 437 conditions. Scientia Horticulturae 232:1-12 DOI 10.1016/j.scienta.2017.12.041.

438 Arduini, I., Baldanzi, M., and Pampana, S. 2019. Reduced growth and nitrogen uptake during 439 waterlogging at tillering permanently affect yield components in late sown oats. Frontiers in 440 Plant Science 10:1087 DOI 10.3389/fpls.2019.01087.

441 Aydogan, C., and Turhan, E. 2015. Changes in morphological and physiological traits and 442 stress-related enzyme activities of green bean (Phaseolus vulgaris L.) genotypes in response to 443 waterlogging stress and recovery treatment. Horticulture Environment and Biotechnology 444 56:391-401 DOI 10.1007/s13580-015-0127-9.

445 Bailey-Serres, J., Lee, S.C., and Brinton, E. 2012. Waterproofing crops: effective flooding 446 survival strategies. Plant Physiology 160:1698-1709 DOI 10.1104/pp.112.208173.

447 Bishi, S.K., Lokesh, K., Mahatma, M.K., Khatediya, N., Chauhan, S.M., and Misra, J.B. 448 2015. Quality traits of Indian peanut cultivars and their utility as nutritional and functional food. 449 Food Chemistry 167:107-114 DOI 10.1016/j.foodchem.2014.06.076.

450 Bishnoi, N.R., and Krishnamoorthy, H.N. 1992. Effect of waterlogging and gibberellic acid on 451 leaf gas exchange in peanut (Arachis hypogaea L.). Journal of Plant Physiology 139:503-505 452 DOI 10.1016/S0176-1617(11)80502-X.

453 Ciancio, N., Miralles, D.J., Striker, G.G., and Abeledo, L.G. 2021. Plant growth rate after, 454 and not during, waterlogging better correlates to yield responses in wheat and barley. Journal of 455 Agronomy and Crop Science 207:304-316 DOI 10.1111/jac.12472. 
456 Galle, A., Haldimann, P., and Feller, U. 2007. Photosynthetic performance and water relations

457 in young pubescent oak (Quercus pubescens) trees during drought stress and recovery. New

458 phytologist 174:799-810 DOI 10.1111/j.1469-8137.2007.02047.x.

459 Gao, J., Su, Y., Yu, M., Huang, Y., Wang, F., and Shen, A. 2021. Potassium alleviates post-

460 anthesis photosynthetic reductions in winter wheat caused by waterlogging at the stem

461 elongation stage. Frontiers in Plant Science 11:607475 DOI 10.3389/fpls.2020.607475.

462 Garrity, D.P., and Pernito, R. 1996. Mungbean response to surface drainage when grown as a

463 pre-rice crop on waterlog-prone ricelands. Agricultural water management 29:299-314 DOI

464 10.1016/0378-3774(95)01200-1.

465 Hossain, M.A., Araki, H., and Takahashi, T. 2011. Poor grain filling induced by waterlogging

466 is similar to that in abnormal early ripening in wheat in Western Japan. Field Crops Research

467 123:100-108 DOI 10.1016/j.fcr.2011.05.005.

468 Hossain, Z., López-Climent, M.F., Arbona, V., Pérez-Clemente, R.M., and Gómez-

469 Cadenas, A. 2009. Modulation of the antioxidant system in citrus under waterlogging and

470 subsequent drainage. Journal of Plant Physiology 166:1391-1404 DOI

471 10.1016/j.jplph.2009.02.012.

472 Hu, J., Ren, B., Dong, S., Liu, P., Zhao, B., and Zhang, J. 2020. Comparative proteomic

473 analysis reveals that exogenous 6-benzyladenine (6-BA) improves the defense system activity of

474 waterlogged summer maize. BMC Plant Biology 20:44 DOI 10.1186/s12870-020-2261-5.

475 Irving, L.J., Sheng, Y.B., Woolley, D., and Matthew, C. 2007. Physiological effects of

476 waterlogging on two lucerne varieties grown under glasshouse conditions. Journal of Agronomy

477 and Crop Science 193:345-356 DOI 10.1111/j.1439-037X.2007.00277.x.

478 Köksal, E.S. 2011. Hyperspectral reflectance data processing through cluster and principal

479 component analysis for estimating irrigation and yield related indicators. Agricultural Water

480 Management 98:1317-1328 DOI 10.1016/j.agwat.2011.03.014.

481 Latif, S., Pfannstiel, J., Makkar, H.P.S., and Becker, K. 2013. Amino acid composition,

482 antinutrients and allergens in the peanut protein fraction obtained by an aqueous enzymatic

483 process. Food Chemistry 136:213-217 DOI 10.1016/j.foodchem.2012.07.120.

484 Li, W., Mo, W., Ashraf, U., Li, G., Wen, T., Abrar, M., Gao, L., Liu, J., and Hu, J. 2018.

485 Evaluation of physiological indices of waterlogging tolerance of different maize varieties in 
486 South China. Applied Ecology and Environmental Research 16:2059-2072 DOI

487 10.15666/aeer/1602_20592072.

488 Li, Z., Zhong, Y., Bai, D., Lin, M., Qi, X., and Fang, J. 2020. Comparative analysis of 489 physiological traits of three Actinidia valvata Dunn genotypes during waterlogging and post490 waterlogging recovery. Horticulture Environment and Biotechnology 61:825-836 DOI 491 10.1007/s13580-020-00276-0.

492 Liu, C., Gong, X., Wang, H., Dang, K., Deng, X., and Feng, B. 2020. Low-nitrogen tolerance 493 comprehensive evaluation and physiological response to nitrogen stress in broomcorn millet 494 (Panicum miliaceum L.) seedling. Plant Physiology and Biochemistry 151:233-242 DOI 495 10.1016/j.plaphy.2020.03.027.

496 Liu, Y., TanG, B., Zheng, Y., Ma, K., Xu, S., and Qiu, F. 2010. Screening methods for 497 waterlogging tolerance at maize (Zea mays L.) seedling Stage. Agricultural Sciences in China 498 9:362-369 DOI 10.1016/S1671-2927(09)60105-X.

499 Pancardo, P., Hernandez-Nolasco, J.A., Wister, M.A., and Garcia-Constantino, M. 2021. 500 Dynamic membership functions for context-based fuzzy systems. IEEE Access 9:29665-29676 501 DOI10.1109/ACCESS.2021.3058943.

502 Pereira, E.S., Silva, O.N., Filho, A.P., Felipe, J.P., Alves, G.A.R., and Lobato, A.K.S. 2015. 503 Antioxidant enzymes efficiently control leaf and root cell damage in young Euterpe oleracea 504 plants exposed to waterlogging. Indian Journal of Plant Physiology 20:213-219 DOI $50510.1007 / \mathrm{s} 40502-015-0162-7$.

506 Pompeiano, A., Huarancca Reyes, T., Moles, T.M., Guglielminetti, L., and Scartazza, A. 507 2019. Photosynthetic and growth responses of Arundo donax L. plantlets under different oxygen 508 deficiency stresses and reoxygenation. Frontiers in Plant Science 10:408 DOI 509 10.3389/fpls.2019.00408.

510 Rivas, R., Falcão, H.M., Ribeiro, R.V., Machado, E.C., Pimentel, C., and Santos, M.G.

511 2016. Drought tolerance in cowpea species is driven by less sensitivity of leaf gas exchange to 512 water deficit and rapid recovery of photosynthesis after rehydration. South African Journal of 513 Botany 103:101-107 DOI 10.1016/j.sajb.2015.08.008.

514 Schiermeier, Q. 2011. Increased flood risk linked to global warming. Nature 470:316 DOI $51510.1038 / 470316 a$. 
516 Seymen, M. 2021. How does the flooding stress occurring in different harvest times affect the

517 morpho-physiological and biochemical characteristics of spinach? Scientia Horticulturae

518 275:109713 DOI 10.1016/j.scienta.2020.109713.

519 Shi, Q., Yin, Y., Wang, Z., Fan, W., and Hua, J. 2016. Physiological acclimation of Taxodium

520 hybrid 'Zhongshanshan 118' plants to short-term drought stress and recovery. HortScience

521 51:1159-1166 DOI 10.21273/HORTSCI10997-16.

522 Singh, S., Singh, S.P., Pathak, A.D., and Pandey, N. 2019. Assessment of waterlogging

523 induced physio-biochemical changes in sugarcane varieties and its association with waterlogging

524 tolerance. Journal of Environmental Biology 40:384-392 DOI 10.22438/jeb/40/3/MRN-898.

525 Smethurst, C.F., Garnett, T., and Shabala, S. 2005. Nutritional and chlorophyll fluorescence

526 responses of lucerne (Medicago sativa) to waterlogging and subsequent recovery. Plant and Soil 527 270:31-45 DOI 10.1007/s11104-004-1082-x.

528 Smethurst, C.F., and Shabala, S. 2003. Screening methods for waterlogging tolerance in

529 lucerne: comparative analysis of waterlogging effects on chlorophyll fluorescence,

530 photosynthesis, biomass and chlorophyll content. Functional Plant Biology 30:335 DOI

531 10.1071/FP02192.

532 Striker, G.G., Kotula, L., and Colmer, T.D. 2019. Tolerance to partial and complete

533 submergence in the forage legume Melilotus siculus: an evaluation of 15 accessions for petiole

534 hyponastic response and gas-filled spaces, leaf hydrophobicity and gas films, and root phellem.

535 Annals of Botany 123:169-180 DOI 10.1093/aob/mcy153.

536 Tian, L., Li, J., Bi, W., Zuo, S., Li, L., Li, W., and Sun, L. 2019. Effects of waterlogging

537 stress at different growth stages on the photosynthetic characteristics and grain yield of spring

538 maize (Zea mays L.) under field conditions. Agricultural Water Management 218:250-258 DOI

539 10.1016/j.agwat.2019.03.054.

540 Tian, L., Zhang, Y., Chen, P., Zhang, F., Li, J., Yan, F., Dong, Y., and Feng, B. 2021. How

541 does the waterlogging regime affect crop yield? A global meta-analysis. Frontiers in Plant

542 Science 12:634898 DOI 10.3389/fpls.2021.634898.

543 Wassie, M., Zhang, W., Zhang, Q., Ji, K., and Chen, L. 2019. Effect of heat stress on growth

544 and physiological traits of Alfalfa (Medicago sativa L.) and a comprehensive evaluation for heat

545 tolerance. Agronomy 9:597 DOI 10.3390/agronomy9100597 
546 Wei, W., Li, D., Wang, L., Ding, X., Zhang, Y., Gao, Y., and Zhang, X. 2013. Morpho-

547 anatomical and physiological responses to waterlogging of sesame (Sesamum indicum L.). Plant

548 Science 208:102-111 DOI 10.1016/j.plantsci.2013.03.014.

549 Wu, X., Tang, Y., Li, C., Wu, C., and Huang, G. 2015. Chlorophyll fluorescence and yield

550 responses of winter wheat to waterlogging at different growth stages. Plant production science

551 18:284-294 DOI 10.1626/pps.18.284.

552 Zeng, R., Chen, L., Wang, X., Cao, J., Li, X., Xu, X., Xia, Q., Chen, T., and Zhang, L. 2020.

553 Effect of waterlogging stress on dry matter accumulation, photosynthesis characteristics, yield,

554 and yield components in three different ecotypes of peanut (Arachis hypogaea L.). Agronomy

555 10:1244 DOI 10.3390/agronomy10091244.

556 Zhang, R.D., Zhou, Y.F., Yue, Z.X., Chen, X.F., Cao, X., Xu, X.X., Xing, Y.F., Jiang, B., Ai,

557 X.Y., and Huang, R.D. 2019. Changes in photosynthesis, chloroplast ultrastructure, and

558 antioxidant metabolism in leaves of sorghum under waterlogging stress. Photosynthetica

559 57:1076-1083 DOI 10.32615/ps.2019.124.

560 Zhang, Y., Song, X., Yang, G., Li, Z., Lu, H., Kong, X., Eneji, A.E., and Dong, H. 2015.

561 Physiological and molecular adjustment of cotton to waterlogging at peak-flowering in relation

562 to growth and yield. Field Crops Research 179:164-172 DOI 10.1016/j.fcr.2015.05.001.

563 Zhou, Z., Li, G., Chao, W., Xu, F., Sun, X., and Chen, Z. 2019. Physiological responses and

564 tolerance evaluation of five poplar varieties to waterlogging. Notulae Botanicae Horti

565 Agrobotanici Cluj-Napoca 47:658-667 DOI 10.15835/nbha47311440. 
Figure 1

Hierarchical cluster analysis. (a) Hierarchical cluster analysis based on the D1 value after waterlogging for 7 days to evaluate the waterlogging tolerance of 15 peanut varieties; (b) Hierarchical cluster analysis based on the D2 value after drainage for

(a)

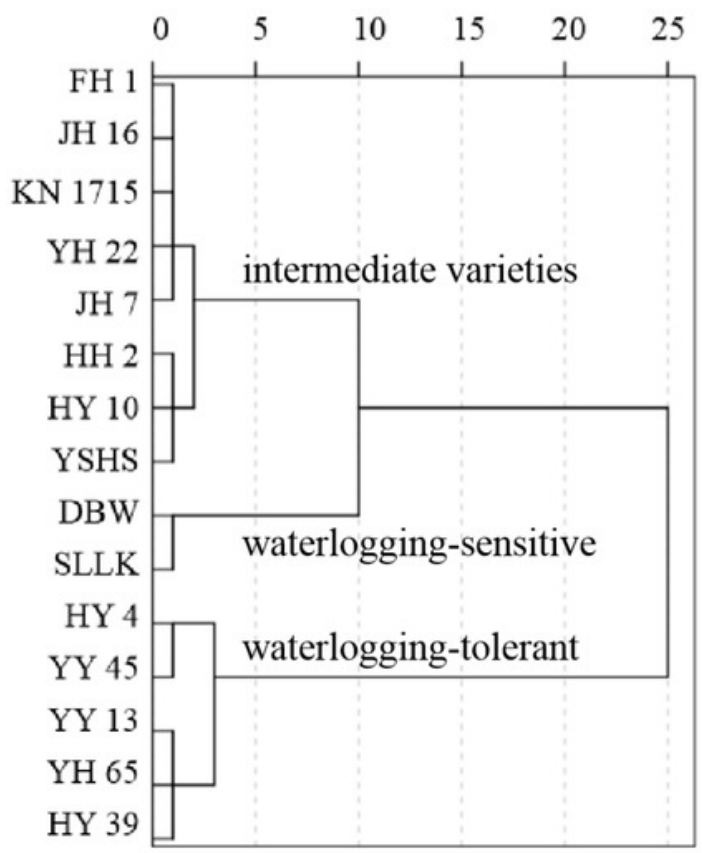

(b)

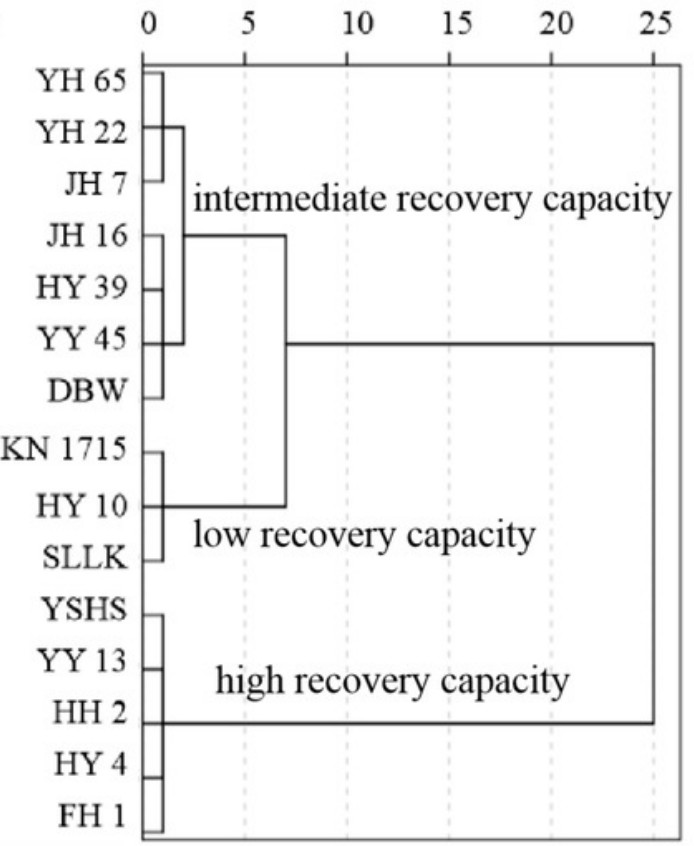


Figure 2

The linear fit between the D1 value, D2 value, and the proportion of reduction in yield and yield components. (a) is between the D1 value and D2 value; (b) is between the D1 value and the proportion of reduction in yield (RY); (c) is between the value of 

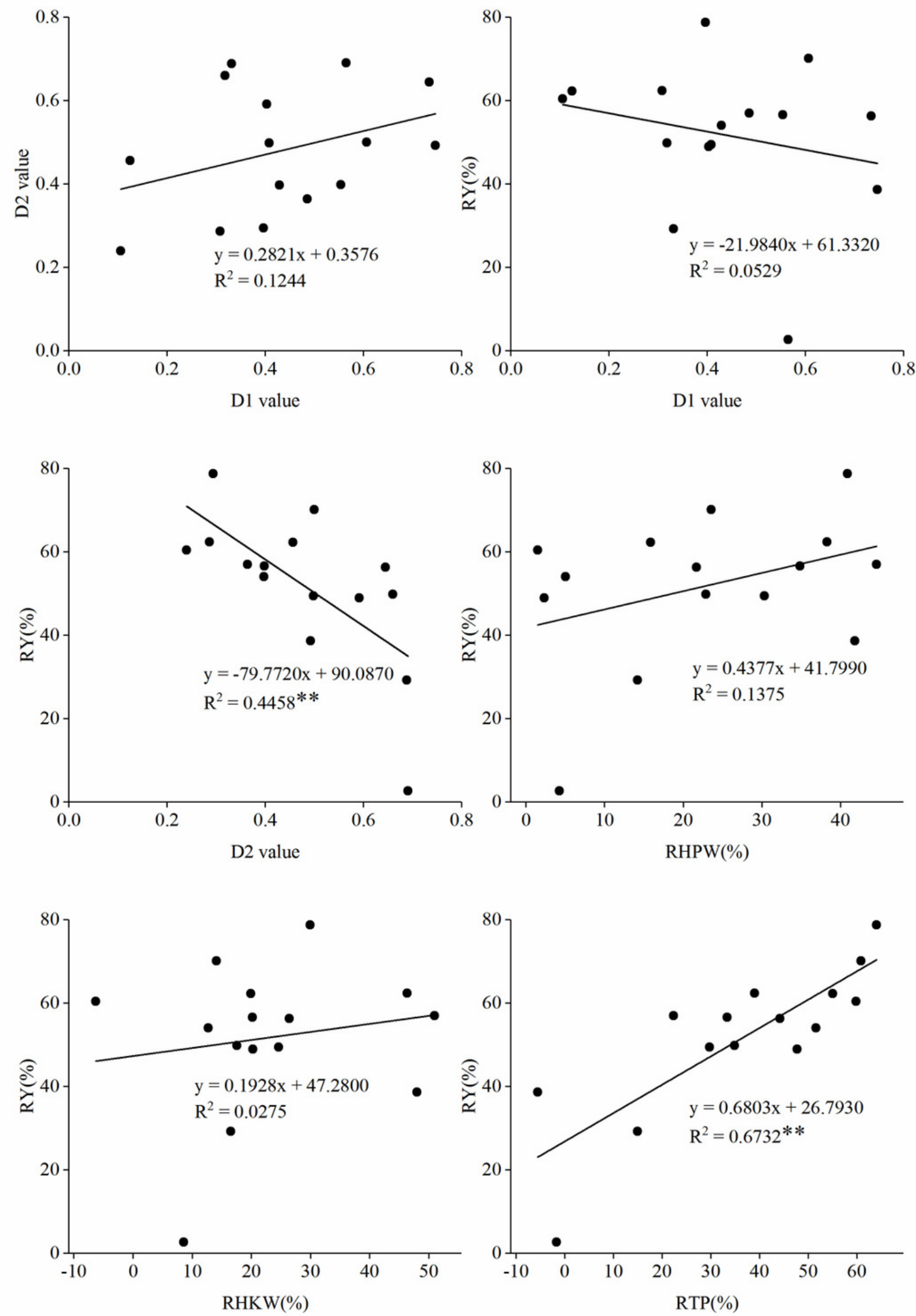


\section{Figure 3}

The proportion of reduction in yield and yield components. (a) The proportion of reduction in yield (RY); (b) The proportion of reduction in HPW (RHPW); (c) The proportion of reduction in HKW (RHKW); (d) The proportion of reduction in TP (RTP).
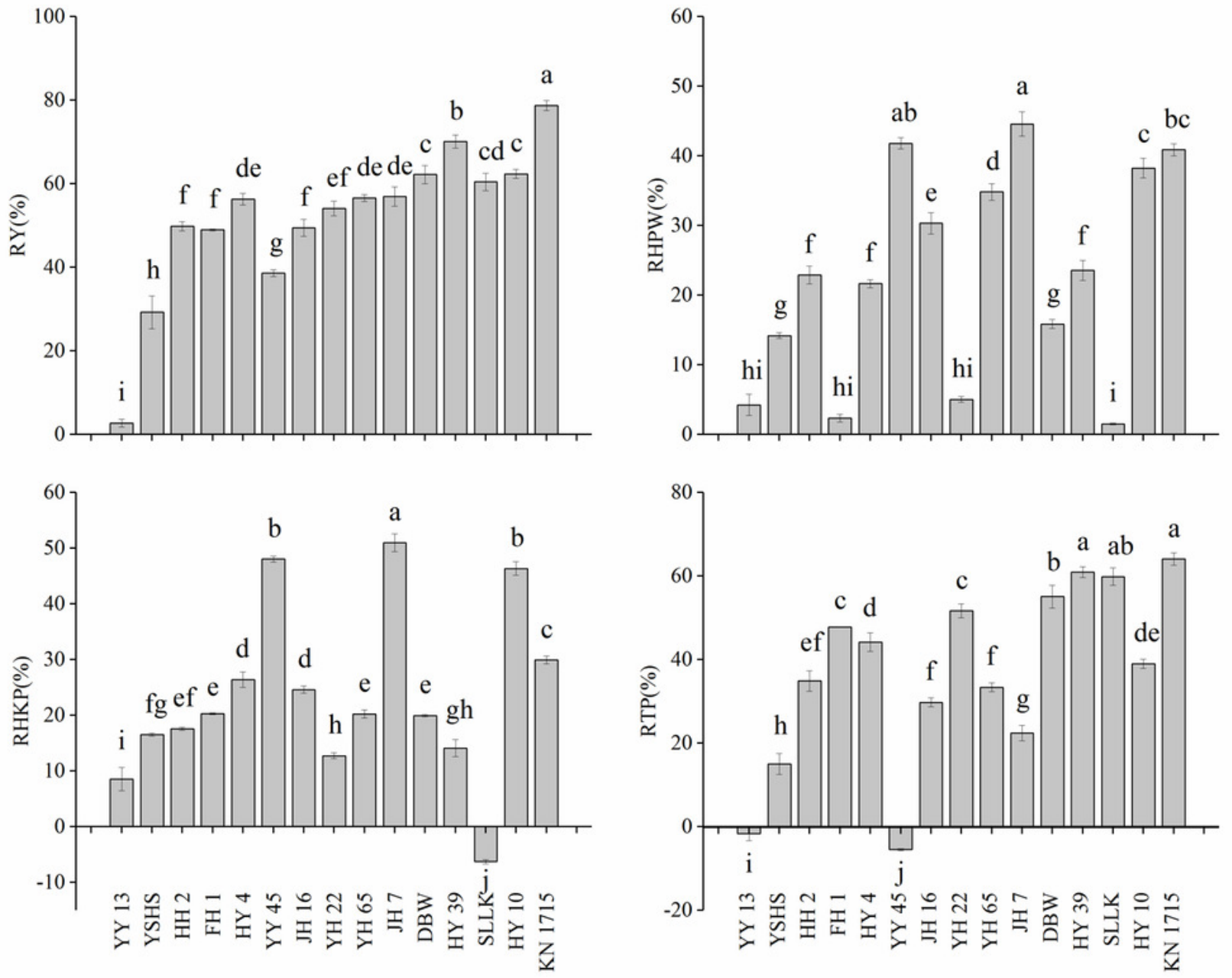


\section{Table $\mathbf{1}$ (on next page)}

Peanut varieties used in this study 


\begin{tabular}{|c|c|c|}
\hline Varieties & Abbreviations & Supplier references \\
\hline Yueyou 13 & YY 13 & Guangdong Academy of Agricultural Sciences Guangzhou, China \\
\hline Hanghua 2 & HH 2 & Guangdong Academy of Agricultural Sciences, Guangzhou, China \\
\hline Yueyou 45 & YY 45 & Guangdong Academy of Agricultural Sciences, Guangzhou, China \\
\hline Heyou 4 & HY 4 & Guangxi Academy of Agricultural Sciences, Nanning, China \\
\hline Heyou 10 & HY 10 & Guangxi Academy of Agricultural Sciences, Nanning, China \\
\hline Yuhua 65 & YH 65 & Henan Academy of Agricultural Sciences, Zhengzhhou, China \\
\hline Yuhua 22 & YH 22 & Henan Academy of Agricultural Sciences, Zhengzhhou, China \\
\hline Dongbeiwang & DBW & Jilin Academy of Agricultural Sciences, Changchun, China \\
\hline Fuhua 1 & FH 1 & Jilin Academy of Agricultural Sciences, Changchun, China \\
\hline Jihua 16 & JH 16 & Liaoning Academy of Agricultural Sciences, Shenyang, China \\
\hline Kainong 1715 & KN 1715 & Shandong Academy of Agricultural Sciences, Jinan, China \\
\hline Huayu 39 & HY 39 & Shandong Academy of Agricultural Sciences, Jinan, China \\
\hline Jinhua 7 & JH 7 & Shanxi Academy of Agricultural Sciences, Taiyuan, China \\
\hline Yushehuasheng & YSHS & Shanxi Academy of Agricultural Sciences, Taiyuan, China \\
\hline Sililanka & SLLK & Sri Lanka \\
\hline
\end{tabular}




\section{Table 2 (on next page)}

Waterlogging tolerance coefficient of physiological indicators of leaves of peanut varieties after waterlogging for 7 days and drainage for 7days, and yield and yield components at the harvest stage. 


\begin{tabular}{|c|c|c|c|c|c|c|c|c|c|c|c|c|c|c|c|}
\hline Varieties & YYHS & YY 13 & HH 2 & KN 1715 & HY 4 & DBW & YH 65 & YH 22 & JH 7 & HY 10 & FH 1 & SLLK & JH 16 & HY 39 & YY 45 \\
\hline REL(W) & 0.785 & 1.808 & 1.320 & 1.039 & 1.086 & 1.092 & 1.098 & 1.718 & 0.585 & 1.002 & 0.940 & 1.980 & 1.133 & 0.968 & 1.260 \\
\hline $\operatorname{MDA}(\mathrm{W})$ & 0.888 & 1.674 & 1.149 & 1.040 & 1.262 & 0.563 & 1.402 & 1.468 & 1.224 & 0.870 & 1.953 & 1.178 & 0.876 & 0.825 & 1.191 \\
\hline $\mathrm{SOD}(\mathrm{W})$ & 1.727 & 0.958 & 1.443 & 1.745 & 2.264 & 0.555 & 1.679 & 3.125 & 1.241 & 1.099 & 0.993 & 0.962 & 1.693 & 1.148 & 1.285 \\
\hline CAT(W) & 0.931 & 1.669 & 1.558 & 0.975 & 0.955 & 0.683 & 1.917 & 1.243 & 0.893 & 2.466 & 8.216 & 1.862 & 1.759 & 0.869 & 9.530 \\
\hline$\Phi_{P S I}(\mathrm{~W})$ & 0.992 & 1.102 & 0.991 & 0.962 & 1.256 & 0.987 & 1.028 & 1.006 & 1.033 & 1.002 & 1.015 & 0.966 & 0.996 & 1.104 & 1.250 \\
\hline $\mathrm{Fv} / \mathrm{Fm}(\mathrm{W})$ & 0.987 & 1.002 & 0.972 & 0.999 & 0.998 & 0.971 & 0.984 & 0.964 & 0.978 & 0.984 & 0.959 & 0.951 & 1.001 & 1.037 & 1.024 \\
\hline NPQ(W) & 1.684 & 0.954 & 1.954 & 1.214 & 0.368 & 1.850 & 1.405 & 2.847 & 1.276 & 1.444 & 2.215 & 1.925 & 1.201 & 0.243 & 0.100 \\
\hline $\mathrm{qL}(\mathrm{W})$ & 1.045 & 1.333 & 1.122 & 0.916 & 1.114 & 1.133 & 1.162 & 1.221 & 1.149 & 1.087 & 1.252 & 1.053 & 1.027 & 0.885 & 1.071 \\
\hline $\operatorname{SPAD}(\mathrm{W})$ & 0.895 & 0.987 & 0.919 & 0.971 & 1.038 & 0.787 & 1.128 & 0.925 & 1.094 & 0.892 & 0.912 & 0.702 & 0.955 & 1.116 & 1.027 \\
\hline REL(D) & 0.966 & 1.134 & 1.064 & 0.951 & 1.258 & 0.619 & 1.118 & 0.895 & 0.943 & 0.713 & 0.950 & 1.290 & 0.981 & 0.964 & 1.095 \\
\hline MDA(D) & 1.480 & 1.326 & 2.132 & 1.126 & 1.059 & 0.742 & 1.046 & 1.808 & 1.260 & 0.992 & 1.369 & 1.057 & 0.886 & 1.080 & 0.833 \\
\hline $\operatorname{SOD}(\mathrm{D})$ & 2.983 & 1.36 & 1.734 & 1.282 & 1.376 & 3.062 & 2.451 & 1.042 & 0.531 & 2.203 & 1.883 & 3.562 & 3.086 & 0.756 & 1.227 \\
\hline CAT(D) & 2.700 & 3.059 & 3.648 & 0.395 & 1.001 & 1.838 & 1.454 & 2.065 & 0.851 & 4.067 & 3.500 & 0.725 & 3.141 & 3.334 & 3.534 \\
\hline$\Phi_{P S I}(\mathrm{D})$ & 1.115 & 1.133 & 1.033 & 0.936 & 1.148 & 1.074 & 0.972 & 0.917 & 0.967 & 0.913 & 1.168 & 0.929 & 1.025 & 1.012 & 0.973 \\
\hline $\mathrm{Fv} / \mathrm{Fm}(\mathrm{D})$ & 1.109 & 1.007 & 0.979 & 0.986 & 1.08 & 0.998 & 0.998 & 0.985 & 0.996 & 0.951 & 0.972 & 0.941 & 0.991 & 1.044 & 1.036 \\
\hline NPQ(D) & 0.588 & 0.993 & 1.418 & 1.224 & 0.342 & 0.786 & 1.044 & 1.243 & 1.119 & 2.125 & 1.419 & 2.234 & 0.958 & 0.694 & 0.746 \\
\hline $\mathrm{qL}(\mathrm{D})$ & 0.918 & 1.401 & 1.226 & 0.876 & 1.018 & 1.321 & 0.928 & 0.831 & 0.901 & 0.960 & 0.874 & 1.033 & 1.140 & 0.804 & 0.886 \\
\hline SPAD(D) & 1.135 & 0.776 & 0.925 & 0.920 & 0.995 & 0.670 & 1.012 & 0.916 & 0.891 & 0.858 & 1.133 & 0.704 & 0.979 & 0.983 & 1.164 \\
\hline HPW & 0.858 & 0.957 & 0.771 & 0.591 & 0.783 & 0.841 & 0.652 & 0.950 & 0.554 & 0.617 & 0.977 & 0.985 & 0.697 & 0.764 & 0.582 \\
\hline HKW & 0.835 & 0.915 & 0.824 & 0.701 & 0.736 & 0.800 & 0.798 & 0.872 & 0.490 & 0.536 & 0.797 & 1.063 & 0.754 & 0.859 & 0.519 \\
\hline ТP & 0.850 & 1.017 & 0.651 & 0.359 & 0.558 & 0.449 & 0.666 & 0.483 & 0.776 & 0.610 & 0.522 & 0.401 & 0.702 & 0.391 & 1.055 \\
\hline Y & 0.708 & 0.973 & 0.501 & 0.213 & 0.437 & 0.378 & 0.434 & 0.459 & 0.430 & 0.376 & 0.510 & 0.395 & 0.505 & 0.299 & 0.614 \\
\hline
\end{tabular}

1 Note: REL: relative electrolyte linkage; MDA: malondialdehyde content; SOD: superoxide dismutase activity; CAT: catalase activity; $\Phi_{P S}$ I: PS II actual quantum yield; Fv/Fm: maximum photochemical efficiency;

2 NPQ: non-photochemical quenching; qL: photochemical quenching; SPAD: the soil and plant analysis development; HPW: hundred pods weight; HKW: hundred kernels weight; Y: yield per hectare; TP: the number

3 of total pods per plant; $\mathrm{W}$ : waterlogging for 7 days; D: drainage for 7 days. 
Table 3 (on next page)

Correlation coefficient matrix among all indicators of peanut varieties 


\begin{tabular}{|c|c|c|c|c|c|c|c|c|c|c|c|c|c|c|c|c|c|c|c|c|c|c|}
\hline & $\operatorname{REL}(\mathrm{W})$ & $\mathrm{MDA}(\mathrm{W})$ & $\operatorname{SOD}(\mathrm{W})$ & $\operatorname{CAT}(\mathrm{W})$ & $\Phi_{P S I}(\mathrm{~W})$ & $\mathrm{Fv} / \mathrm{Fm}(\mathrm{W})$ & $\mathrm{NPQ}(\mathrm{W})$ & $\mathrm{qL}(\mathrm{W})$ & $\operatorname{SPAD}(\mathrm{W})$ & $\operatorname{REL(D)}$ & $\mathrm{MDA}(\mathrm{D})$ & $\operatorname{SOD}(\mathrm{D})$ & CAT(D) & $\Phi_{P S I}(\mathrm{D})$ & $\mathrm{Fv} / \mathrm{Fm}(\mathrm{D})$ & $\mathrm{NPQ(D)}$ & $\mathrm{qL}(\mathrm{D})$ & $\operatorname{SPAD}(\mathrm{D})$ & HPW & HKW & TP & $\mathrm{Y}$ \\
\hline $\operatorname{REL}(\mathrm{W})$ & 1 & & & & & & & & & & & & & & & & & & & & & \\
\hline $\mathrm{MDA}(\mathrm{W})$ & 0.293 & 1 & & & & & & & & & & & & & & & & & & & & \\
\hline $\mathrm{SOD}(\mathrm{W})$ & 0.110 & 0.181 & 1 & & & & & & & & & & & & & & & & & & & \\
\hline $\mathrm{CAT}(\mathrm{W})$ & -0.007 & 0.446 & -0.216 & 1 & & & & & & & & & & & & & & & & & & \\
\hline$\Phi_{P S I}(\mathrm{~W})$ & -0.017 & 0.174 & 0.114 & 0.377 & 1 & & & & & & & & & & & & & & & & & \\
\hline $\mathrm{Fv} / \mathrm{Fm}(\mathrm{W})$ & -0.244 & -0.280 & -0.021 & 0.082 & $0.605^{*}$ & 1 & & & & & & & & & & & & & & & & \\
\hline $\mathrm{NPQ}(\mathrm{W})$ & 0.245 & 0.218 & 0.199 & -0.139 & $-0.754^{* *}$ & $-0.878^{* *}$ & 1 & & & & & & & & & & & & & & & \\
\hline $\mathrm{qL}(\mathrm{W})$ & 0.317 & $0.699 * *$ & 0.013 & 0.207 & 0.062 & -0.473 & 0.402 & 1 & & & & & & & & & & & & & & \\
\hline $\operatorname{SPAD}(\mathrm{W})$ & -0.445 & 0.186 & 0.248 & 0.030 & 0.506 & $0.646^{* *}$ & $-0.585^{*}$ & -0.073 & 1 & & & & & & & & & & & & & \\
\hline $\operatorname{REL}(\mathrm{D})$ & 0.422 & 0.449 & 0.190 & 0.100 & 0.422 & 0.090 & -0.311 & 0.053 & 0.179 & 1 & & & & & & & & & & & & \\
\hline MDA(D) & 0.181 & 0.381 & 0.409 & -0.149 & -0.265 & -0.362 & $0.534^{*}$ & 0.315 & -0.037 & 0.118 & 1 & & & & & & & & & & & \\
\hline $\operatorname{SOD}(\mathrm{D})$ & 0.191 & -0.320 & -0.274 & -0.096 & -0.464 & -0.428 & 0.341 & -0.056 & $-0.689^{* *}$ & -0.036 & -0.268 & 1 & & & & & & & & & & \\
\hline CAT(D) & -0.043 & 0.020 & -0.229 & 0.443 & 0.115 & 0.269 & -0.067 & 0.129 & 0.020 & -0.273 & 0.173 & -0.017 & 1 & & & & & & & & & \\
\hline$\Phi_{P S Y}(\mathrm{D})$ & -0.173 & 0.280 & -0.188 & 0.123 & 0.296 & 0.049 & -0.122 & 0.370 & 0.026 & 0.138 & 0.076 & 0.071 & 0.212 & 1 & & & & & & & & \\
\hline $\mathrm{Fv} / \mathrm{Fm}(\mathrm{D})$ & -0.375 & -0.181 & 0.254 & -0.089 & $0.547^{*}$ & $0.534^{*}$ & -0.492 & -0.193 & 0.396 & 0.178 & -0.039 & -0.164 & 0.008 & 0.508 & 1 & & & & & & & \\
\hline $\mathrm{NPQ}(\mathrm{D})$ & 0.373 & 0.132 & -0.236 & 0.069 & $-0.564^{*}$ & $-0.581^{*}$ & 0.501 & 0.081 & $-0.537^{*}$ & -0.059 & 0.138 & 0.283 & 0.048 & $-.531^{*}$ & $-.857^{* * *}$ & 1 & & & & & & \\
\hline $\mathrm{qL}(\mathrm{D})$ & 0.374 & -0.100 & -0.400 & -0.251 & -0.081 & -0.140 & 0.053 & 0.405 & -0.354 & -0.009 & 0.003 & 0.352 & 0.120 & 0.385 & -0.140 & -0.021 & 1 & & & & & \\
\hline $\operatorname{SPAD}(\mathrm{D})$ & -0.463 & 0.263 & 0.323 & $0.553^{*}$ & 0.381 & 0.363 & -0.259 & -0.131 & 0.494 & 0.181 & 0.122 & -0.245 & 0.337 & 0.242 & $0.518^{*}$ & -0.415 & $-0.588^{*}$ & 1 & & & & \\
\hline $\mathrm{HPW}$ & $0.582^{*}$ & 0.386 & 0.011 & -0.032 & -0.175 & -0.469 & 0.509 & 0.454 & $-0.547^{*}$ & 0.174 & 0.341 & 0.303 & 0.068 & 0.451 & -0.050 & 0.126 & 0.286 & -0.236 & 1 & & & \\
\hline HKW & $0.645 * *$ & 0.162 & 0.033 & -0.306 & -0.303 & -0.311 & 0.377 & 0.110 & -0.438 & 0.352 & 0.276 & 0.417 & -0.128 & 0.224 & -0.067 & 0.125 & 0.292 & -0.329 & $0.829 * *$ & 1 & & \\
\hline TP & -0.019 & 0.215 & -0.098 & 0.360 & 0.429 & 0.313 & -0.341 & 0.397 & 0.295 & 0.209 & 0.022 & -0.120 & 0.381 & 0.238 & 0.345 & -0.295 & 0.249 & 0.338 & -0.190 & -0.343 & 1 & \\
\hline $\mathrm{Y}$ & 0.298 & 0.410 & -0.085 & 0.214 & 0.262 & 0.082 & -0.060 & $0.621^{*}$ & 0.012 & 0.273 & 0.227 & 0.034 & 0.388 & $0.518^{*}$ & 0.303 & -0.231 & 0.468 & 0.138 & 0.370 & 0.166 & $0.820^{* *}$ & 1 \\
\hline
\end{tabular}

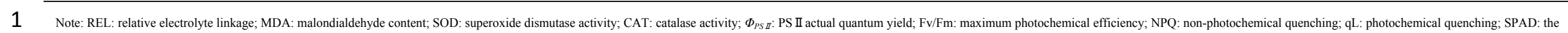

2 soil and plant analysis development; HPW: hundred pods weight; HKW: hundred kernels weight; Y: yield per hectare; TP: the number of total pods per plant; W: waterlogging for 7 days; D: drainage for 7 days. * represents a significant difference ( $p<0.05$ ) and ** represents a significant

3 difference $(p<0.01)$. 


\section{Table 4 (on next page)}

Eigenvalue and contribution of each comprehensive index after waterlogging for 7 days and loading matrix of each component. 


\begin{tabular}{|c|c|c|c|c|}
\hline \multirow{2}{*}{ Items } & \multirow{2}{*}{ Traits } & \multicolumn{3}{|c|}{ Principal component } \\
\hline & & 1 & 2 & 3 \\
\hline \multicolumn{2}{|l|}{ Eigenvalue } & 3.308 & 2.168 & 1.299 \\
\hline \multicolumn{2}{|c|}{ Contributive ratio $(\%)$} & 36.759 & 24.092 & 14.438 \\
\hline \multicolumn{2}{|c|}{ Cumulative contribution $(\%)$} & 36.759 & 60.851 & 75.289 \\
\hline \multirow{9}{*}{ Loading matrix of each } & REL(W) & -0.448 & 0.293 & -0.009 \\
\hline & $\operatorname{MDA}(\mathrm{W})$ & -0.273 & 0.880 & 0.104 \\
\hline & $\mathrm{SOD}(\mathrm{W})$ & -0.032 & 0.163 & 0.893 \\
\hline & $\mathrm{CAT}(\mathrm{W})$ & 0.122 & 0.622 & -0.546 \\
\hline & $\Phi_{P S I I}(\mathrm{~W})$ & 0.699 & 0.546 & -0.022 \\
\hline & $\mathrm{Fv} / \mathrm{Fm}(\mathrm{W})$ & 0.932 & -0.011 & 0.009 \\
\hline & NPQ(W) & -0.938 & -0.067 & 0.173 \\
\hline & $\mathrm{qL}(\mathrm{W})$ & -0.494 & 0.710 & 0.012 \\
\hline & SPAD(W) & 0.732 & 0.297 & 0.403 \\
\hline
\end{tabular}

1 Note: REL: relative electrolyte linkage; MDA: malondialdehyde content; SOD: superoxide

2 dismutase activity; CAT: catalase activity; $\Phi_{P S ~ I I}$ : PS II actual quantum yield; Fv/Fm: maximum

3 photochemical efficiency; NPQ: non-photochemical quenching; qL: photochemical quenching;

4 SPAD: the soil and plant analysis development; $\mathrm{W}$ : waterlogging for 7 days. 


\section{Table 5 (on next page)}

Value of each comprehensive indicators $\left[C I_{x}\right]$, subordinate function values $\mu\left(X_{j}\right)$, comprehensive evaluation value (D) and order after waterlogging for 7 days 


\begin{tabular}{ccccccccc}
\hline Varieties & $\boldsymbol{C I}_{\boldsymbol{1}}$ & $\boldsymbol{C I}_{\boldsymbol{2}}$ & $\boldsymbol{C I}_{\boldsymbol{3}}$ & $\boldsymbol{u}\left(\boldsymbol{X}_{\boldsymbol{1}}\right)$ & $\boldsymbol{u}\left(\boldsymbol{X}_{2}\right)$ & $\boldsymbol{u}\left(\boldsymbol{X}_{3}\right)$ & D1 value & Order \\
\hline YYHS & -0.1830 & -1.4448 & 0.4030 & 0.4179 & 0.1117 & 0.4779 & 0.3314 & 11 \\
YY 13 & -0.1998 & 2.2024 & -0.3663 & 0.4151 & 0.9584 & 0.2910 & 0.5652 & 4 \\
HH 2 & -1.2226 & -0.3380 & 0.1238 & 0.2493 & 0.3687 & 0.4101 & 0.3183 & 12 \\
KN 1715 & 0.6199 & -1.5418 & 0.5873 & 0.5480 & 0.0892 & 0.5227 & 0.3963 & 10 \\
HY 4 & 2.0087 & 1.0857 & 1.2827 & 0.7731 & 0.6992 & 0.6917 & 0.7339 & 2 \\
DBW & -1.2791 & -1.9260 & -1.3938 & 0.2402 & 0.0000 & 0.0413 & 0.1252 & 14 \\
YH 65 & 0.2387 & 0.7659 & 0.9428 & 0.4862 & 0.6249 & 0.6091 & 0.5542 & 5 \\
YH 22 & -2.5916 & 1.0813 & 2.5514 & 0.0274 & 0.6982 & 1.0000 & 0.4286 & 7 \\
JH 7 & 0.5206 & -0.1202 & 0.4115 & 0.5319 & 0.4192 & 0.4800 & 0.4859 & 6 \\
HY 10 & -0.2201 & -1.0123 & -0.7174 & 0.4118 & 0.2121 & 0.2057 & 0.3084 & 13 \\
FH 1 & -1.8226 & 2.3815 & -1.3738 & 0.1521 & 1.0000 & 0.0462 & 0.4031 & 9 \\
SLLK & -2.7607 & -0.7288 & -1.2058 & 0.0000 & 0.2779 & 0.0870 & 0.1056 & 15 \\
JH 16 & 0.5218 & -1.0908 & 0.2897 & 0.5321 & 0.1939 & 0.4504 & 0.4082 & 8 \\
HY 39 & 3.4080 & -1.3344 & 0.0287 & 1.0000 & 0.1374 & 0.3870 & 0.6064 & 3 \\
YY 45 & 2.9616 & 2.0203 & -1.5638 & 0.9276 & 0.9161 & 0.0000 & 0.7461 & 1 \\
\hline Index weight & & & & 0.4882 & 0.3200 & 0.1918 & & \\
\hline Not CI valu & & & & &
\end{tabular}

1 Note: " $\boldsymbol{C r}$ ' values were determined by principal component analysis (PCA) and the scores of the 2 comprehensive indicators. 
Table 6(on next page)

Eigenvalue and contribution of each comprehensive index after drainage for 7 days and loading matrix of each component. 


\begin{tabular}{|c|c|c|c|c|c|}
\hline \multirow{2}{*}{ Items } & \multirow{2}{*}{ Traits } & \multicolumn{4}{|c|}{ Principal component } \\
\hline & & 1 & 2 & 3 & 4 \\
\hline \multicolumn{2}{|l|}{ Eigenvalue } & 2.744 & 1.765 & 1.385 & 1.172 \\
\hline \multicolumn{2}{|c|}{ Contributive ratio $(\%)$} & 30.493 & 19.614 & 15.385 & 13.022 \\
\hline \multicolumn{2}{|c|}{ Cumulative contribution (\%) } & 30.493 & 50.106 & 65.492 & 78.514 \\
\hline \multirow{9}{*}{$\begin{array}{c}\text { Loading matrix of each } \\
\text { component }\end{array}$} & REL(D) & 0.237 & -0.017 & -0.414 & 0.694 \\
\hline & MDA(D) & 0.079 & -0.234 & 0.51 & 0.702 \\
\hline & $\mathrm{SOD}(\mathrm{D})$ & -0.371 & 0.544 & -0.074 & -0.186 \\
\hline & CAT(D) & 0.155 & 0.055 & 0.879 & -0.202 \\
\hline & $\Phi_{P S ~ I I}(\mathrm{D})$ & 0.599 & 0.630 & 0.195 & 0.156 \\
\hline & $\mathrm{Fv} / \mathrm{Fm}(\mathrm{D})$ & 0.897 & 0.160 & -0.176 & -0.089 \\
\hline & NPQ(D) & -0.857 & -0.254 & 0.201 & 0.155 \\
\hline & qL(D) & -0.248 & 0.869 & 0.165 & 0.229 \\
\hline & SPAD(D) & 0.749 & -0.411 & 0.198 & -0.109 \\
\hline
\end{tabular}

1 Note: REL: relative electrolyte linkage; MDA: malondialdehyde content; SOD: superoxide

2 dismutase activity; CAT: catalase activity; $\Phi_{P S ~ I I}$ : PS II actual quantum yield; Fv/Fm: maximum

3 photochemical efficiency; NPQ: non-photochemical quenching; qL: photochemical quenching; 4 SPAD: the soil and plant analysis development; D: drainage for 7 days. 


\section{Table 7 (on next page)}

Value of each comprehensive indicators $\left[C I_{x}\right]$, subordinate function values $\mu\left(X_{j}\right)$, comprehensive evaluation value (D) and order after drainage for 7 days 


\begin{tabular}{|c|c|c|c|c|c|c|c|c|c|c|}
\hline Varieties & $C I_{1}$ & $\mathrm{CI}_{2}$ & $\mathrm{CI}_{3}$ & $\mathrm{CI}_{4}$ & $u\left(X_{I}\right)$ & $u\left(X_{2}\right)$ & $u\left(X_{3}\right)$ & $u\left(X_{4}\right)$ & D2 value & Order \\
\hline YYHS & 2.6275 & 0.6039 & 0.3227 & -0.3109 & 1.0000 & 0.5311 & 0.5354 & 0.3765 & 0.6884 & 2 \\
\hline YY 13 & 0.1073 & 2.1252 & 0.6002 & 1.3939 & 0.5728 & 0.8538 & 0.6085 & 0.8193 & 0.6909 & 1 \\
\hline HH 2 & -0.4490 & 0.2235 & 2.0866 & 2.0893 & 0.4784 & 0.4504 & 1.0000 & 1.0000 & 0.6601 & 3 \\
\hline KN 1715 & -0.6668 & -1.2722 & -1.3463 & -0.1249 & 0.4416 & 0.1331 & 0.0959 & 0.4248 & 0.2940 & 13 \\
\hline HY 4 & 2.5849 & 0.8691 & -1.6734 & 0.8036 & 0.9928 & 0.5874 & 0.0097 & 0.6660 & 0.6447 & 4 \\
\hline DBW & -1.2761 & 2.8141 & -0.2517 & -1.7602 & 0.3383 & 1.0000 & 0.3842 & 0.0000 & 0.4565 & 9 \\
\hline YH 65 & -0.0271 & -0.4158 & -1.0897 & -0.0510 & 0.5500 & 0.3148 & 0.1635 & 0.4440 & 0.3979 & 10 \\
\hline YH 22 & -0.5213 & -1.8997 & 0.5226 & 0.5798 & 0.4663 & 0.0000 & 0.5881 & 0.6079 & 0.3971 & 11 \\
\hline JH 7 & -0.2020 & -1.2573 & -0.8692 & 0.2047 & 0.5204 & 0.1363 & 0.2215 & 0.5104 & 0.3642 & 12 \\
\hline HY 10 & -2.4813 & -0.7824 & 1.4902 & -1.5247 & 0.1340 & 0.2370 & 0.8429 & 0.0612 & 0.2866 & 14 \\
\hline FH 1 & 0.7142 & -0.3302 & 1.5690 & 0.0256 & 0.6757 & 0.3329 & 0.8637 & 0.4639 & 0.5918 & 5 \\
\hline SLLK & -3.2722 & 0.2331 & -1.7103 & 1.1852 & 0.0000 & 0.4525 & 0.0000 & 0.7651 & 0.2399 & 15 \\
\hline JH 16 & -0.2353 & 1.1281 & 0.1943 & -0.8512 & 0.5148 & 0.6423 & 0.5016 & 0.2361 & 0.4978 & 7 \\
\hline HY 39 & 1.4682 & -1.0098 & 0.1862 & -0.7596 & 0.8035 & 0.1888 & 0.4995 & 0.2599 & 0.5002 & 6 \\
\hline YY 45 & 1.6298 & -1.0297 & -0.0311 & -0.8998 & 0.8309 & 0.1846 & 0.4423 & 0.2235 & 0.4925 & 8 \\
\hline Inde & & & & & 0.3884 & 0.2498 & 0.1960 & 0.1659 & & \\
\hline
\end{tabular}

1 Note: “ $\boldsymbol{C r}$ ' values were determined by principal component analysis (PCA) and the scores of the comprehensive indicators. 


\section{Table 8 (on next page)}

Correlation analysis between D1 value and physiological indexes measured after 7 days of waterlogging 


\begin{tabular}{cccccccccc}
\hline & $\mathrm{REL}(\mathrm{W})$ & $\mathrm{MDA}(\mathrm{W})$ & $\mathrm{SOD}(\mathrm{W})$ & $\mathrm{CAT}(\mathrm{W})$ & $\Phi_{P S I}(\mathrm{~W}$ & $\mathrm{Fv} / \mathrm{Fm}(\mathrm{W})$ & $\mathrm{NPQ}(\mathrm{W})$ & $\mathrm{qL}(\mathrm{W})$ & $\mathrm{SPAD}(\mathrm{W})$ \\
\hline $\mathrm{D} 1$ & -0.175 & 0.332 & 0.322 & 0.300 & $0.845^{* *}$ & $0.708^{* *}$ & $-0.707^{* *}$ & 0.038 & $0.845^{* *}$ \\
\hline
\end{tabular}

1 Note: REL: relative electrolyte linkage; MDA: malondialdehyde content; SOD: superoxide dismutase activity;

2 CAT: catalase activity; $\Phi_{P S}$ I: PS I actual quantum yield; Fv/Fm: maximum photochemical efficiency; NPQ:

3 non-photochemical quenching; qL: photochemical quenching; SPAD: the soil and plant analysis development;

$4 \mathrm{~W}$ : waterlogging for 7 days. * represents a significant difference $(p<0.05)$ and $* *$ represents a significant 5 difference $(p<0.01)$ 
Table 9 (on next page)

Correlation analysis between D2 value and physiological indexes measured after 7 days of drainage 


\begin{tabular}{cccccccccc}
\hline & REL(D) & MDA(D) & SOD(D) & CAT(D) & $\Phi_{P S I}(\mathrm{D})$ & Fv/Fm(D) & NPQ(D) & qL(D) & SPAD(D) \\
\hline D2 & 0.212 & 0.370 & -0.102 & 0.429 & $0.855^{* *}$ & $0.625^{*}$ & $-0.609^{*}$ & 0.364 & 0.396 \\
\hline
\end{tabular}

1 Note: REL: relative electrolyte linkage; MDA: malondialdehyde content; SOD: superoxide dismutase activity;

2 CAT: catalase activity; ФPS II : PS II actual quantum yield; Fv/Fm: maximum photochemical efficiency; NPQ:

3 non-photochemical quenching; qL: photochemical quenching; SPAD: the soil and plant analysis development;

4 D: drainage for 7 days. * represents a significant difference $(p<0.05)$ and $* *$ represents a significant 5 difference $(p<0.01)$ 